\title{
A Method to Predict and Visualize the Wheel and Work Surface Topography in Surface Grinding
}

\author{
Dinesh Setti ${ }^{\mathrm{a}}$, Benjamin Kirsch ${ }^{\mathrm{b}}$ and Jan. C. Aurich ${ }^{\mathrm{c}}$ \\ Institute for Manufacturing Technology and Production Systems, University of Kaiserslautern, \\ Gottlieb-Daimler-Str., 67663, Kaiserslautern, Germany \\ adinesh.setti@mv.uni-kl.de, benjamin.kirsch@mv.uni-kl.de, 'jan.aurich@mv.uni-kl.de
}

Keywords: Surface grinding, wheel topography, surface topography, simulation, visualization.

\begin{abstract}
Visualization of work surface topography through simulations is very challenging task in grinding process due to the complexity of wheel-work interactions with a very high number of cutting points (grits). Kinematic mapping of abrasive grits on a three-dimensional wheel topography enables the evaluation of ground surface topography through simulations. In this paper, a method for generating the ground surface topography based on wheel specifications is presented. Abrasive grits size, abrasives volume percentage and their nature of distribution on the wheel surface are considered in the modeling and visualization of wheel topography. The simulation results of ground surface topographies prove the feasibility of the developed method.
\end{abstract}

\section{Introduction}

The generation of the surface in grinding processes is the result of the trajectories of each and every abrasive grit protruding the grinding wheel and penetrating the workpiece surface. To increase product quality and efficiency when grinding, the better understanding through simulations requires a representation of the wheel surface that closely matches reality [1,2]. Several experimental techniques like imprint, profilometry and microscopy have been used for characterizing the grinding wheel topography $[3,4]$. Of all techniques, profilometry is the simplest and most attractive method for characterization of the wheel surface topography. Two-dimensional profiles of wheel surfaces obtained by profilometry have been modeled on a microscopic scale using various statistical approaches [5]. However, characterization of bigger size wheels topography is tedious and involves errors of measurement. Moreover, it is also difficult to digitize the measured data in a specified format, which is required for the work surface simulations. Thus, most of the research [4, 6] has centered on obtaining the surface topography of larger sized wheels by simulation. One common approach adopted by several researchers is meshing the grinding wheel surface with grit shapes such as spherical, conical, and pyramidal. The protrusion heights of the abrasive grits is stochastic, and their position on the wheel surface is randomly distributed. Since the wheel topography has a direct impact on the quality of the process, and having a proper wheel topography model could facilitate easier prediction of process responses such as grinding forces [7] and temperature [8] etc. In the present work, a method for simulating the ground surface topography has been developed based on stochastic modelling of the wheel topography using MATLAB, which facilitates to study and analyze the grinding process quantitatively.

\section{Grinding Wheel Topography Generation}

Grinding wheels consist of hard abrasive grits like diamond or corundum embedded in the bond material like resin or metal. The grit positions and protrusion heights are randomly distributed in lateral and radial directions, respectively. The wheel topography and kinematic conditions define the grit-work interaction and ultimately the generated ground surface topography. In the process of describing a grinding wheel, the term 'mesh size' is used to specify the size of the abrasive grits. The term mesh number indicates the number of linear openings per square inch on the sieves, which were used to sort the abrasive grits in the grinding wheel manufacturing process. It is a nondimensional quantity. Based on the analyses and experimental work, several researchers [9] have 
defined a theoretical upper bound and average value of grits size related to mesh size as given below.

$$
\begin{aligned}
& \mathrm{d}_{\mathrm{g}}(\text { in } \mathrm{mm})=68 \mathrm{M}^{-1.4} \\
& \mathrm{~d}_{\mathrm{g} \max }(\text { in } \mathrm{mm})=15.2 \mathrm{M}^{-1}
\end{aligned}
$$

where $d_{g}$ is average grit size, $M$ is mesh size and $d_{g \text { max }}$ is maximum grit size. From the literature also maximum, minimum and average grit size values for different mesh sizes can be found as given in Table 1.

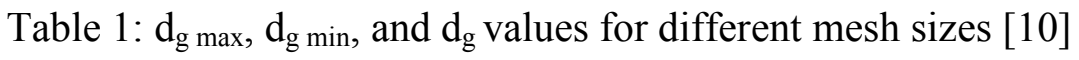

\begin{tabular}{|c|c|c|c|c|c|c|c|c|c|c|c|}
\hline Mesh size\# & 20 & 24 & 30 & 36 & 46 & 54 & 60 & 70 & 80 & 90 & 100 \\
\hline $\mathrm{d}_{\mathrm{g} \max }(\mathrm{mm})$ & 0.938 & 0.762 & 0.589 & 0.476 & 0.354 & 0.291 & 0.255 & 0.211 & 0.178 & 0.152 & 0.142 \\
\hline $\mathrm{d}_{\mathrm{g} \min }(\mathrm{mm})$ & 0.762 & 0.589 & 0.476 & 0.354 & 0.291 & 0.255 & 0.211 & 0.178 & 0.152 & 0.142 & 0.114 \\
\hline $\mathrm{d}_{\mathrm{g}}(\mathrm{mm})$ & 0.850 & 0.676 & 0.532 & 0.415 & 0.323 & 0.273 & 0.233 & 0.194 & 0.165 & 0.147 & 0.128 \\
\hline
\end{tabular}

It is reported that maximum and average grit size values are very close to the maximum and average grain protrusion heights respectively [11]. The grits protrusion heights distribution can be considered as either uniform distribution or normal (Gaussian) distribution. Here, to generate the wheel topography, the entire grinding wheel surface is divided into a rectangular mesh with an equal interval of ' $\mathrm{d}_{\mathrm{g}}$ ' in lateral (y-axis), and peripheral directions (x-axis) and a grit center is located at the center of each opening. In an ideal case, if the wheel surface is covered with $100 \%$ of abrasive grits, the distance between the each grain center will be equal as shown in Fig 1(b). However, abrasive grits percentage on the wheel surface varies according to the wheel structure number, which is used to specify the abrasives volume percentage in a grinding wheel as given in Table 2.
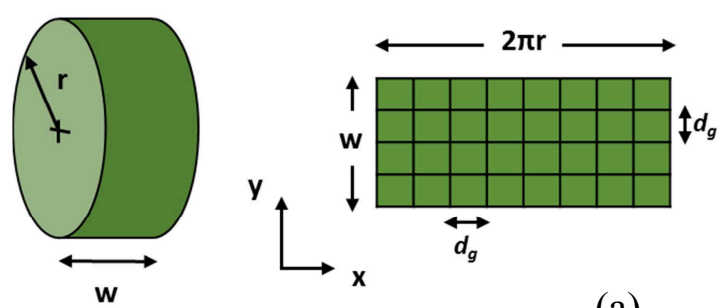

(a)

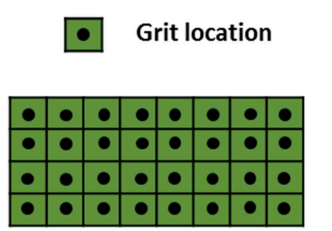

(b)

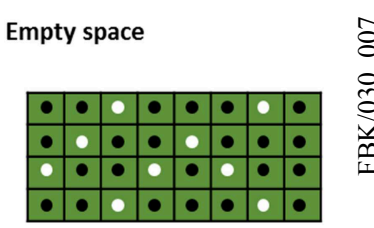

(c)

Fig. 1: Meshing (a), and allocation of grits on a wheel surface (b) with $100 \%$ concentration (c) with specific concentration

Table 2: Abrasive volume percentage based on structure number [12]

\begin{tabular}{|l|l|l|l|l|l|l|l|l|l|}
\hline Structure number & 0 & 1 & 2 & 3 & 4 & 5 & 6 & 7 & 8 \\
\hline Abrasive grits volume percentage & 68 & 64 & 60 & 58 & 56 & 54 & 52 & 50 & 48 \\
\hline
\end{tabular}

Hence, to consider the grits volume percentage effect, empty spaces have been created randomly according to the grits volume percentage (Fig.1(c)), and in this location, a grit protrusion height value of " 0 " was assigned. In the last step, for the remaining grit locations, grit protrusion height values have been assigned (in z-axis) with specific mean and standard deviations according to the nature of the protrusion heights distribution. That is, for a Gaussian or normal distribution, mean and standard deviation values can be calculated using the following equations.

$$
\begin{aligned}
& \mu=h_{g}=d_{g}(\text { conventional abrasive wheels; }[11]) \\
& \mu=h_{g}=0.67 d_{g}(\text { for electroplated bonded wheels) } \\
& \sigma=\left(h_{g} \max -h_{g}\right) / 3=\left(d_{g} \max -d_{g}\right) / 3
\end{aligned}
$$

where $\mu$ is the mean girts size value, $h_{\mathrm{g}}$ is the mean protrusion height, $\sigma$ is the standard deviation, and $h_{\mathrm{g} \max }$ is the maximum grit protrusion height. 
For a uniform distribution, mean and standard deviation values can be calculated using the following equations.

$$
\begin{aligned}
& \mu=h_{g} \\
& \sigma=\frac{h_{g \text { max }}-h_{g}}{\sqrt{3}}
\end{aligned}
$$

Figure 2 shows the simulated wheel topographies with different grit sizes $(a, b)$, concentrations (a, c) and distributions $(b, d)$. Moreover, the developed simulation method has been compared with available experimentally measured grit protrusion heights data as shown in Figure 3. It can be observed that the developed wheel topography simulation method is able to take care of variations in grit protrusion heights according to the actual wheel topography.
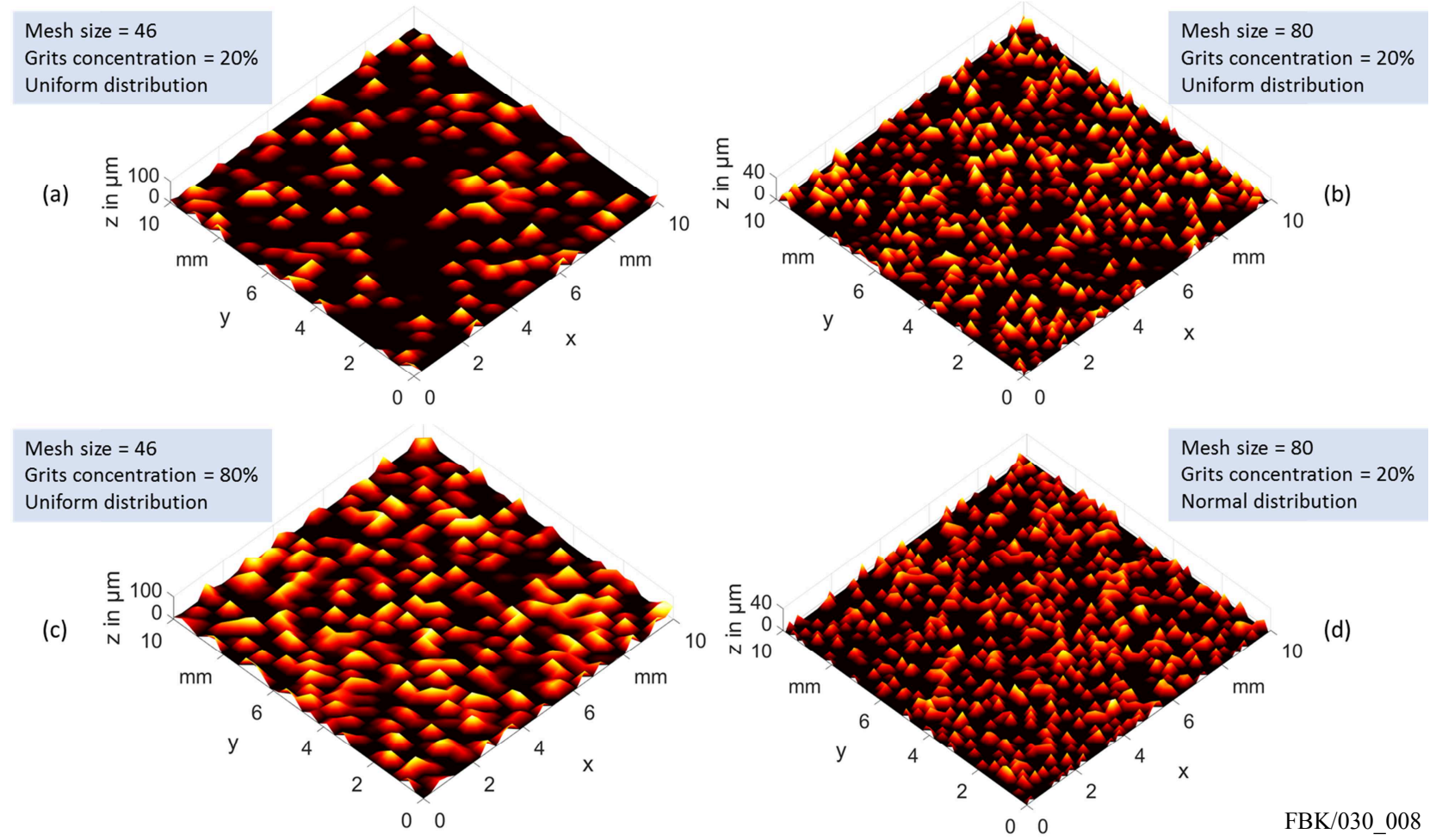

Fig. 2: Simulated wheel topographies with different mesh sizes, grits concentrations, and distributions

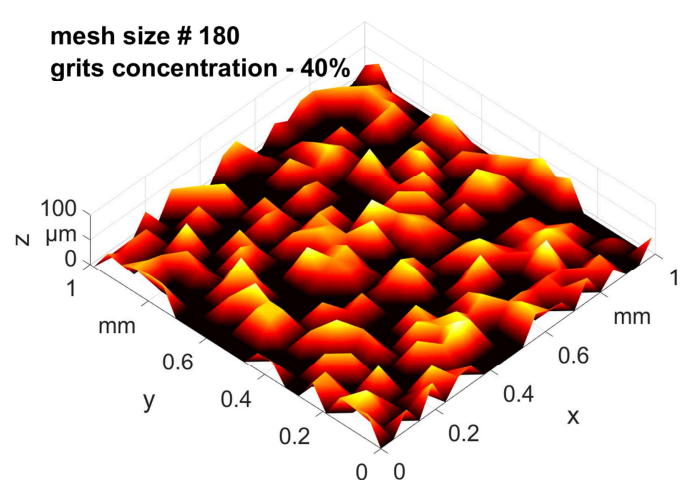

(a)

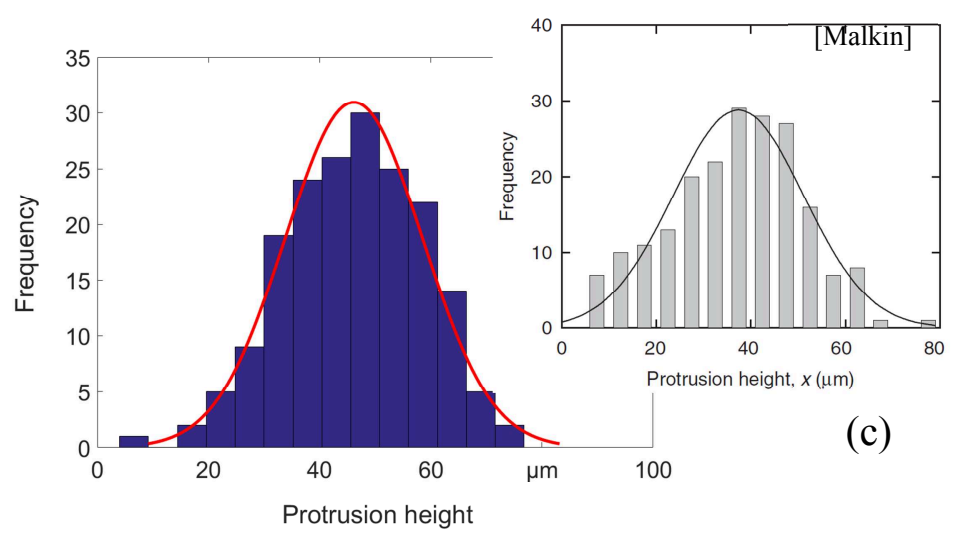

(b)

FBK/030_009

Fig. 3: Comparison of simulated 180 mesh size wheel topography with optically measured 180 mesh size electroplated cBN wheel topography (a) simulated topography (b) protrusion heights distribution in simulated topography (c) optically measured protrusion heights distribution [9] 


\section{Simulation of work surface topography}

To simulate the work surface topography, abrasive grits on the simulated wheel topography are considered as sets of points on the circumference of the wheel having coordinates in $\mathrm{x}, \mathrm{y}$, and $\mathrm{z}$ directions. The $\mathrm{x}$-direction is along the circumference of the wheel, the y-direction is across the width of the wheel, and the z-direction is along the radial direction of the wheel as shown in Figure 4. The grinding wheel is divided into ' $n$ ' equal slices depending on the mean grit size and required simulation area. Each grit on the wheel surface follows a trajectory path with certain a cutting speed $\left(\mathrm{v}_{\mathrm{ci}}\right)$ and at the same time workpiece moves with a feed rate $\left(\mathrm{v}_{\mathrm{w}}\right)$ against to the grit as shown in Figure 4.

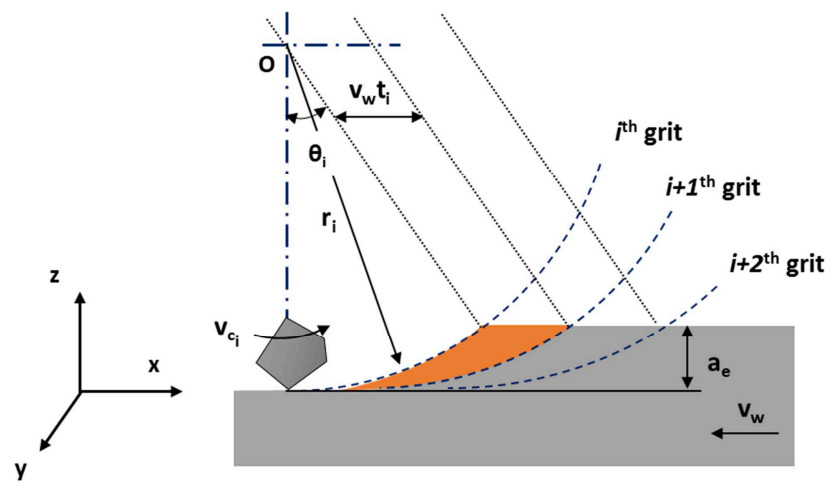

FBK/030_0010

Fig. 4: Grit trajectories and kinematic movements between grit and workpiece

During the trajectory path, the coordinates of the grit continuously change with its angular position $\left(\theta_{i}\right)$ which depends on the cutting time $\left(t_{i}\right)$. Hence, the coordinates of the $i^{\text {th }}$ grit during the trajectory path can be expressed as function of the cutting time $\left(\mathrm{t}_{\mathrm{i}}\right)$ as given below [13]:

$$
\begin{aligned}
& x_{i}\left(t_{i}\right)=r_{i} \sin \left(\frac{v_{c_{i} t_{i}}}{r_{i}}-\theta_{i}\right)+v_{w} t_{i}, \\
& z_{i}\left(t_{i}\right)=-r_{i} \cos \left(\frac{v_{c_{i} t_{i}}}{r_{i}}-\theta_{i}\right),
\end{aligned}
$$

where $t_{i}$ will be in between 0 to $t_{i \max }, t_{i \max }$ is the maximum cutting time for a specific trajectory distance, $r_{i}$ is the radial distance of the $i^{\text {th }}$ grit from the center of the wheel, and it can be calculated using the following formula.

$$
r_{i}=h_{i}+\frac{d}{2},
$$

where $h_{i}$ is the $i^{\text {th }}$ grit protrusion height and $d$ is the nominal diameter of the grinding wheel. For a given depth of cut $\left(a_{e}\right)$, the angular position $\left(\theta_{i}\right)$ of the $i^{\text {th }}$ grit can be calculated as follows

$$
\theta_{i}=\sin ^{-1}\left(\sqrt{\frac{r_{i}^{2}-\left(r_{i}-a_{e}\right)^{2}}{r_{i}}}\right) \text {. }
$$

Cutting time-dependent trajectories of each grit on the wheel surface are calculated and mapped into a spatial coordinate system and plotted using MATLAB programming to get a $3 \mathrm{D}$ view of the ground surface. For each and every $(\mathrm{x}, \mathrm{y})$-coordinate, there is a chance to have several z-coordinates as several grains may pass over the same location of the workpiece surface again and again. In the present work by assuming that each grit on the wheel surface in the trajectory path has the capability to remove the material from the work surface within the depth of cut value. In a real process, there will be a specific minimum cutting depth value for each grit (minimum chip thickness), above which chip formation takes place and below which only rubbing and ploughing actions occur. Hence, in future work the effect of the minimum chip thickness for each grit will be considered which not only represents the actual process but also reflects physical aspects of the grinding process. Rubbing and ploughing actions smoothen the surface, hence the results presented here exaggerate the roughness of the surface. Figure 5 shows the simulated $3 \mathrm{D}$ and $2 \mathrm{D}$ surface 
profiles at various locations. As indicated in the figure, the simulations show finished surfaces, the grinding zone as well as the unaltered work surface for a depth of cut of $30 \mu \mathrm{m}$. The 2D surface profile height variation in the grinding zone is evidence for this ongoing material removal action. To quantitatively evaluate the developed method, simulations have been done for different wheel specifications. Variations in the surface topography and in the 2D surface profiles and calculated arithmetic mean surface roughness values for $3 D$ surface $\left(S_{a}\right)$ are shown in Figure 5 and 6 . Fine grits (Fig. 5a) and higher concentrations (Fig. 5b) result into small and narrow scratches, coarse grits and lower concentration (Fig. 5c) into deep and wide scratches. Figure 6 shows the variations in ' $\mathrm{S}_{\mathrm{a}}$ ' value with different kinematic conditions and variation in these values in accordance to common knowledge shows the feasibility of the proposed method.

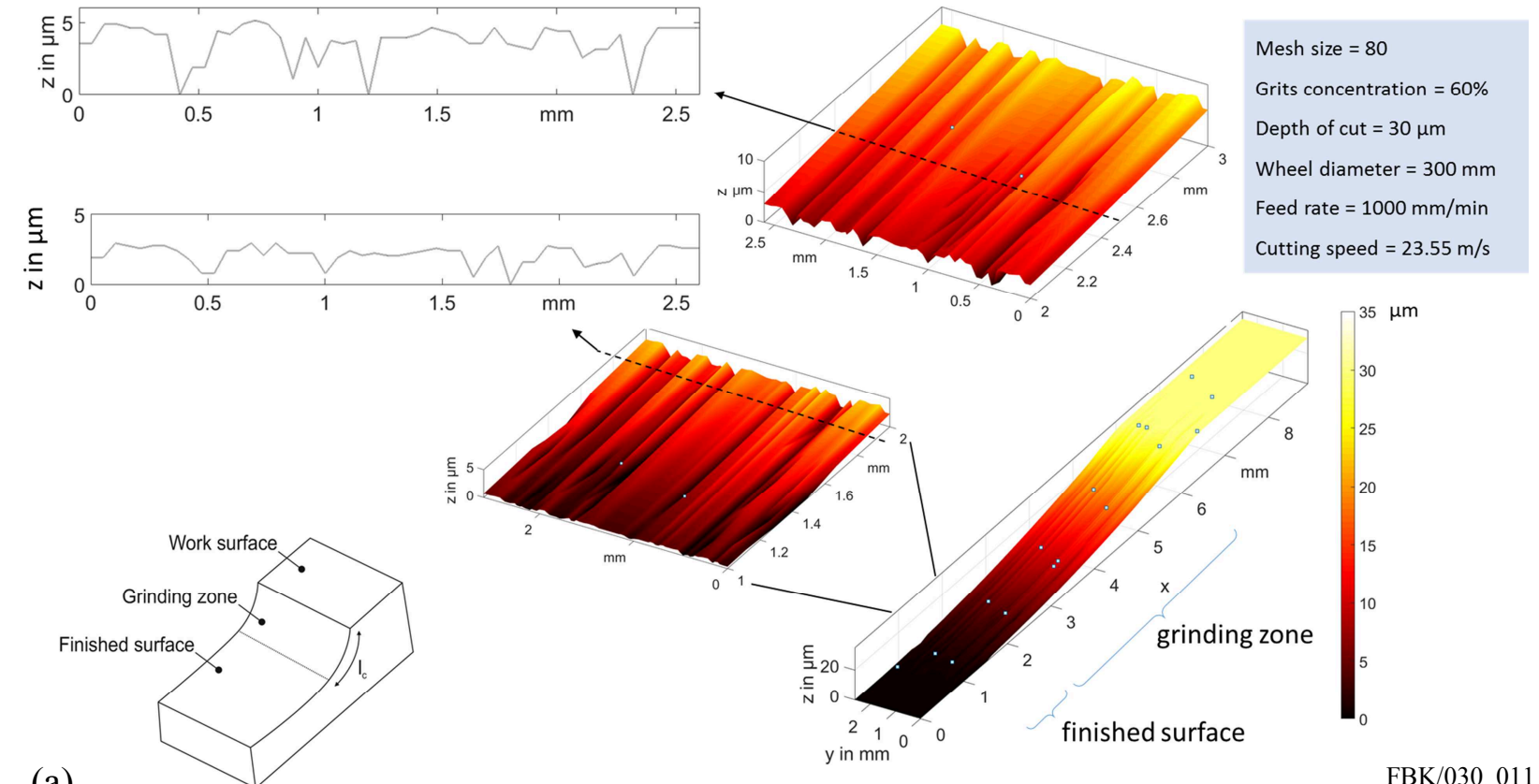

(a)

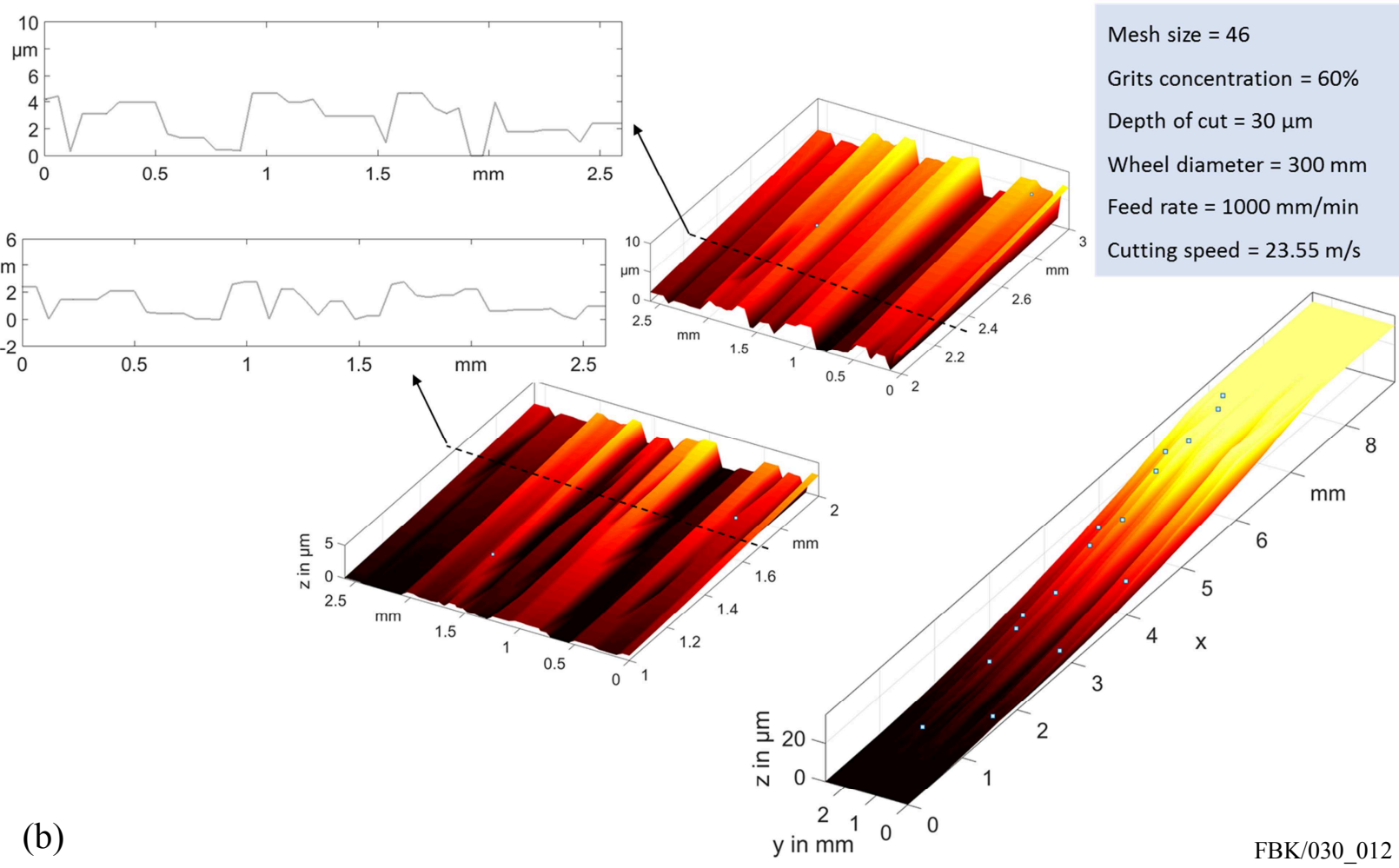




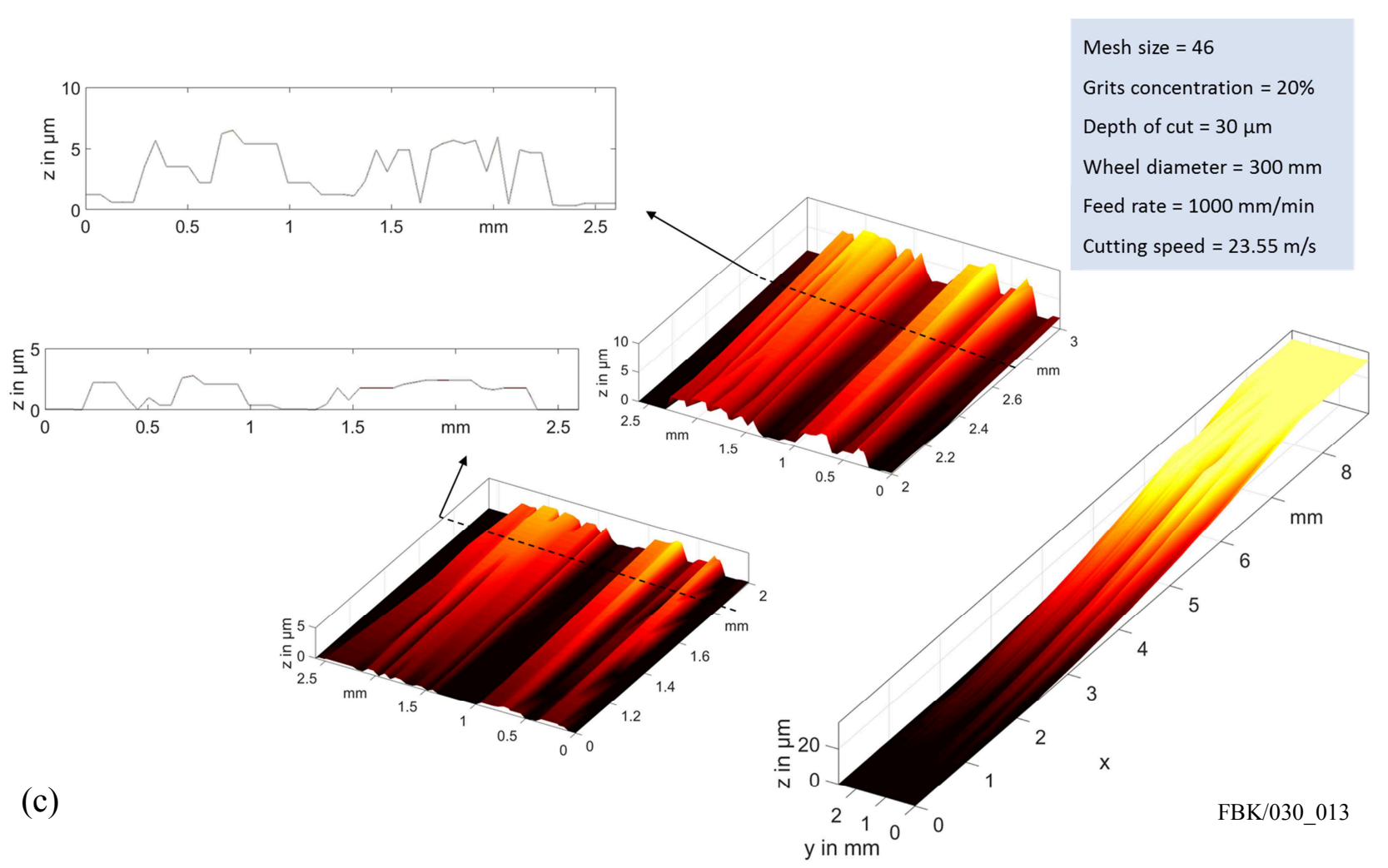

Fig. 5: Simulated grinding zone 3D topography and 2D surface profiles at various positions in the grinding zone with different wheel specifications
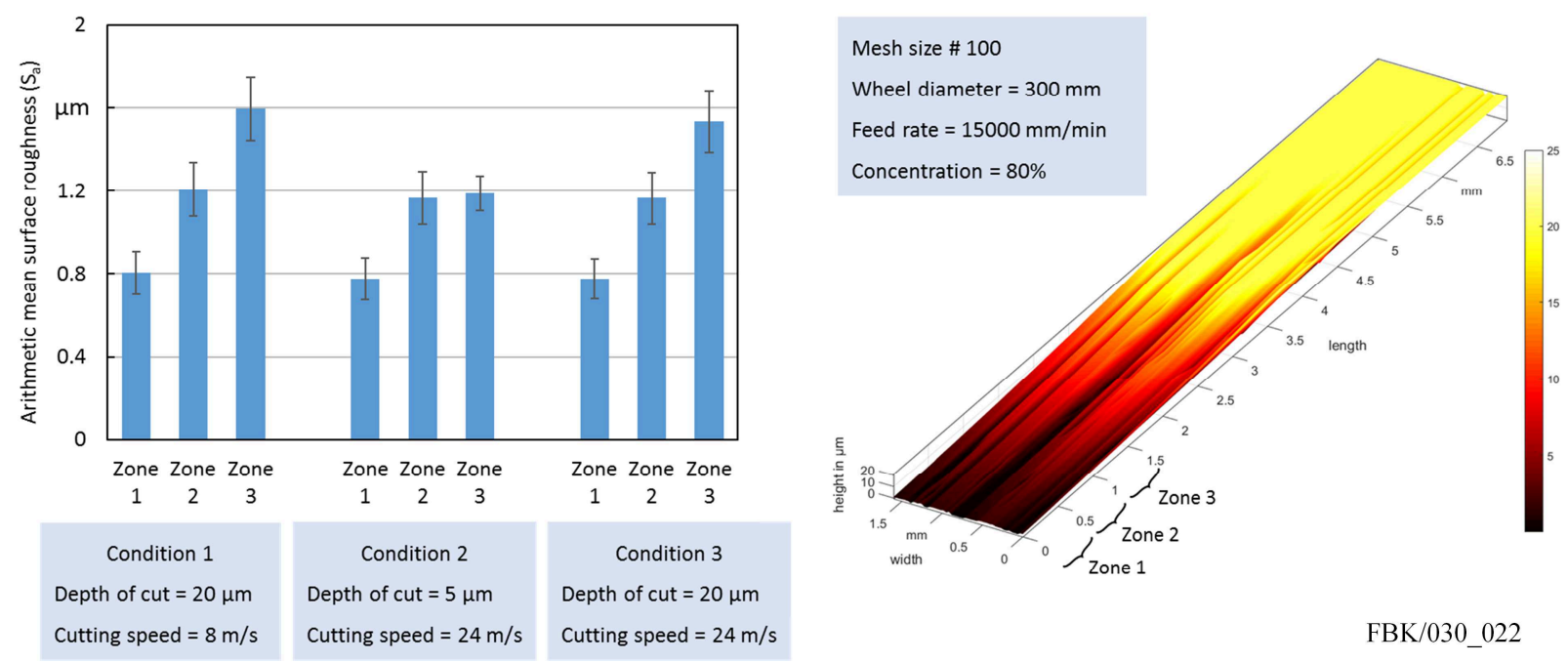

Fig. 6: Variation in arithmetic mean surface roughness values with different kinematic conditions and different zones

The above simulation results (Fig. 5) showed the influence of wheel specifications on the finished surface topography. Results showed in Fig. 6 gives an insight into the influence of kinematic conditions on roughness value. Moreover, the influence of measured zone on roughness value also can be observed. For condition 1 and 3, the contact length value is approximately $2.5 \mathrm{~mm}$ and the roughness values measured within this region $(0-1.5 \mathrm{~mm}$; zone $1: 0-0.5 \mathrm{~mm}$, zone $2: 0.5-1 \mathrm{~mm}$, zone 3: $1-1.5 \mathrm{~mm}$ ) showed a gradual increase. Whereas, for second condition, the contact length value is approximately $1.2 \mathrm{~mm}$ and the values measured within this region showed an initial variation and then steady. That is, the characterization of the simulated surface topography enables the quantitative evaluation of results. Further, it can be used to improve the ground surface quality and to optimize the grinding process by choosing appropriate wheel specifications and/or process parameters. 


\section{Conclusion}

A method for the simulation of the 3D wheel and work surface topography was developed. The wheel topography considers grit size, concentration and nature of the protrusion heights distribution. Based on kinematic interactions between grit and work material, the ground surface topography was simulated. The feasibility of the simulation was verified by considering $2 \mathrm{D}$ and $3 \mathrm{D}$ surface profiles for various wheel specifications. Minimum chip thickness effects will be considered in future work to incorporate the physical aspects of grinding.

\section{Acknowledgement}

The research presented in this paper was funded by the Deutsche Forschungsgemeinschaft DFG within the International Research Training Group IRTG 2057 "Physical Modeling for Virtual Manufacturing Systems and Processes".

\section{References}

[1] J.C. Aurich, D. Biermann, H. Blum, C. Brecher, C. Carstensen, B. Denkena, F. Klocke, M. Kröger, P. Steinmann, K. Weinert, Modelling and simulation of process: Machine interaction in grinding, Prod. Eng. Res. Devel. 3 (2009) 111-120.

[2] J.C. Aurich, B. Kirsch, Kinematic simulation of high-performance grinding for analysis of chip parameters of single grains, CIRP Journal of Manufacturing Science and Technology 5 (2012) 164-174.

[3] K. Steffens, W. König, Closed Loop Simulation of Grinding, CIRP Annals - Manufacturing Technology 32 (1983) 255-259.

[4] T.A. Nguyen, D.L. Butler, Simulation of precision grinding process, part 1: Generation of the grinding wheel surface, International Journal of Machine Tools and Manufacture 45 (2005) 1321-1328.

[5] I. Inasaki, Grinding Process Simulation Based on the Wheel Topography Measurement, CIRP Annals - Manufacturing Technology 45 (1996) 347-350.

[6] P. Koshy, V.K. Jain, G.K. Lal, Stochastic simulation approach to modelling diamond wheel topography, International Journal of Machine Tools and Manufacture 37 (1997) 751-761.

[7] R.L. Hecker, I.M. Ramoneda, S.Y. Liang, Analysis of Wheel Topography and Grit Force for Grinding Process Modeling, Journal of Manufacturing Processes 5 (2003) 13-23.

[8] H.N. Li, D. Axinte, On a stochastically grain-discretised model for 2D/3D temperature mapping prediction in grinding, International Journal of Machine Tools and Manufacture 116 (2017) 60-76.

[9] S. Malkin, C. Guo, Grinding technology: Theory and application of machining with abrasives, secondnd ed., Industrial Press, New York, 2008.

[10] Z.B. Hou, R. Komanduri, On the mechanics of the grinding process - Part I. Stochastic nature of the grinding process, International Journal of Machine Tools and Manufacture 43 (2003) 1579-1593.

[11] X. Zhou, F. Xi, Modeling and predicting surface roughness of the grinding process, International Journal of Machine Tools and Manufacture 42 (2002) 969-977.

[12] I.D. Marinescu, Handbook of machining with grinding wheels.

[13] Y. Liu, A. Warkentin, R. Bauer, Y. Gong, Investigation of different grain shapes and dressing to predict surface roughness in grinding using kinematic simulations, Precision Engineering 37 (2013) 758-764. 